Article

\title{
Investigation of Home Energy Management with Advanced Direct Load Control and Optimal Scheduling of Controllable Loads
}

\author{
Kanato Tamashiro $^{1, *}$, Talal Alharbi ${ }^{2} \mathbb{D}$, Alexey Mikhaylov ${ }^{3, *} \mathbb{D}$, Ashraf M. Hemeida ${ }^{4}$, Narayanan Krishnan ${ }^{5}(\mathbb{D}$, \\ Mohammed Elsayed Lotfy ${ }^{1,6}$ (D) and Tomonobu Senjyu ${ }^{1}$ (D) \\ 1 Fuculty of Engineering, University of the Ryukyus, 1 Senbaru, Nishihara-cho, Nakagami, \\ Okinawa 903-0213, Japan; lotfyico2010@gmail.com (M.E.L.); b985542@tec.u-ryukyu.ac.jp (T.S.) \\ 2 Department of Electrical Engineering, College of Engineering, Qassim University, \\ Buraydah 52571, Saudi Arabia; atalal@qu.edu.sa \\ 3 Financial Research Institute, Ministry of Finance of the Russian Federation, 127006 Moscow, Russia \\ 4 Fuculty of Energy Engineering, Awan University, Aswan 81711, Egypt; ashraf@aswu.edu.eg \\ 5 Department of Electrical and Electronics Engineering, SASTRA Deemed University, Thanjavur 613401, India; \\ narayanan@eee.sastra.edu \\ 6 Electrical Power \& Machines Department, Zagazig University, Zagazig 44519, Egypt \\ * Correspondence: k218483@eve.u-ryukyu.ac.jp (K.T.); alexeyfa@yandex.ru (A.M.)
}

check for updates

Citation: Tamashiro, K.; Alharbi, T.; Mikhaylov, A.; Hemeida, A.M.; Krishnan, N.; Lotfy, M.E.; Senjyu, T. Investigation of Home Energy Management with Advanced Direct Load Control and Optimal Scheduling of Controllable Loads. Energies 2021, 14, 7314. https:// doi.org/10.3390/en14217314

Academic Editor: Álvaro Gutiérrez

Received: 27 September 2021

Accepted: 1 November 2021

Published: 4 November 2021

Publisher's Note: MDPI stays neutral with regard to jurisdictional claims in published maps and institutional affiliations.

Copyright: (c) 2021 by the authors. Licensee MDPI, Basel, Switzerland. This article is an open access article distributed under the terms and conditions of the Creative Commons Attribution (CC BY) license (https:/ / creativecommons.org/licenses/by/ $4.0 /)$.

\begin{abstract}
Due to the rapid changes in the energy situation on a global scale, the amount of RES installed using clean renewable energy sources such as Photovoltaic (PV) and Wind-power Generators (WGs) is rapidly increasing. As a result, there has been a great deal of research aimed at promoting the adoption of renewable energy. Research on Demand-side Management (DSM) has also been important in promoting the adoption of RES. However, the massive introduction of PV has changed the shape of the demand curve for electricity, which significantly impacts the operational planning of thermal generators. Therefore, this paper proposes an Advanced Direct Load Control (ADLC) model to temporarily shutdown the electric connection between the power grid and Smart Houses (SHs). The most important feature of the proposed model is that it temporarily shuts down the electric connection with the power grid. The shutdown is performed twice to increase the load demand during daytime hours and reduce the peak load during night-time hours. The proposed model also promotes the self-consumption of the generated power during the shutdown period, which is expected to reduce the operating cost. This paper considers six case studies for $\mathrm{SH}$, and the operational costs and carbon dioxide emissions are compared and discussed. The results show that the $\mathrm{SH}$ with ADLC successfully reduces the operating costs and carbon dioxide emissions.
\end{abstract}

Keywords: smart house; renewable energy; heat pump; advanced direct load control

\section{Introduction}

There has been growing interest in global environmental issues such as global warming and the depletion of fossil fuels in recent years. In response, the Japanese government has announced its Basic Energy Plan, aiming to reduce carbon dioxide emissions by $46 \%$ or more and increase the ratio of zero-emission power sources from $16 \%$ in 2016 to $57 \%$ to $61 \%$ in 2030 . However, due to the effects of the East Japan Earthquake in 2010, nuclear power, one of the zero-emission power sources, is not fully functioning. Therefore, the introduction of Renewable Energy Sources (RES) using clean natural energy such as Photovoltaic (PV) and Wind-power Generators (WGs) is rapidly increasing as an alternative energy source to nuclear power [1]. As a result, many studies have been conducted to promote the introduction of renewable energy sources [2,3]. Therefore, further promotion of the introduction of RES is expected in the future. In particular, the Feed-in Tariff (FIT) system that has been in place since 2012 has increased the amount of PV installed, and it 
is expected to spread to households as well, promoting its introduction as a distributed power source for local production for local consumption.

A Smart House (SH) has been proposed as a demand-side measure for environmental protection. PV and Heat Pump (HP) water heaters are mainly installed in the SH [4], and the operating cost (electricity price) in the house can be reduced by applying the Timeof-Use (ToU) price provided by the electric power company $[5,6]$. In this case, the smart house is self-sufficient in energy using PV and supplies the generated power to the loads in the home. In addition, it is also possible to sell the generated surplus power to the power company. This reduces the amount of electricity purchased from the power company on the demand side, and on days with high solar radiation, it is possible to earn revenue from the power sold. Since the East Japan Earthquake mentioned above, energy supply in times of disaster has become an issue, and the introduction of storage batteries into SHs has been proposed. At present, the introduction of storage batteries in the household sector has not progressed due to their high initial cost, but the price is expected to decrease in the future. In addition, for HPs that use electricity for hot water supply, operating costs can be reduced by starting the system during night-time hours when electricity rates are low. As described above, an SH has various advantages and can bring benefits (lower operating costs) to the consumer side. In addition, it is expected to reduce carbon dioxide emissions by promoting the introduction of RES and reducing the amount of purchased electricity, which could benefit the power system operator as well; thus, creating a win-win relationship.

Renewable energy, especially PV, which is currently being introduced in increasing quantities, is changing the shape of the demand curve for electricity, which has a significant impact on the operational planning of thermal generators $[7,8]$. This phenomenon is called the duck curve, and it results in a significant difference between the peak and off-peak demand periods, which reduces the operational efficiency of thermal generators. As a result, the PV output must be curtailed and its capacity cannot be utilized to the fullest. In addition, the introduction of new renewable energies is going to stagnate and the expansion of their introduction might not be realized, and the goals mentioned above would not be reached. As a countermeasure to these problems, load control is well known, in which peak loads are shifted to times when PV output becomes large, and Demand Response (DR) is used to control power consumption by consumers. Load control can be roughly classified into indirect load control and direct load control. In indirect control, consumers control their electricity consumption by providing incentive information such as electricity rates and demand curves from power companies. On the other hand, direct control involves the direct remote control of devices in the home by the power company. This makes it possible to shift the peak load and increase it when the PV output is at maximum. In addition to peak shifting, Demand-side Management (DSM) such as these can also reduce electricity costs by providing superior appliance control. Therefore, DSM is fundamental research in terms of the cost for power system operators and consumers [9].

For indirect load control, as described above, the power companies use these load controls to reduce peak loads by setting prices for each time period to gain an advantage in power system operation. In this case, customers can reduce the operating cost of the smart house by operating home appliances according to the price setting. In recent years, electricity meters with communication functions such as smart meters have become widespread, and Real-time Pricing (RTP) using these meters has been introduced. This is expected to reduce household electricity bills and improve energy consumption profiles effectively $[10,11]$. However, when the utility company controls the load indirectly as in these cases, there is uncertainty that the effect depends on the electricity consumption behavior of the customer [12,13]. Customers' consumption behavior patterns change depending on their daily lives, seasons, and other factors. Therefore, it is necessary to operate the system in such a way that it can cope with the uncertainty.

On the other hand, direct load control allows the power system operator to control the appliances and adjust the load to achieve a highly efficient generator operation. This is expected to be more effective than indirect control and is considered to be an effective 
method. However, it may be stressful for customers to have their home appliances operated by a power company. Various factors form customers' lifestyles, and the operation of appliances that do not match their lifestyles is detrimental to their comfort. In contrast to previous studies, Ref. [14] proposes a DLC model that takes into account the thermal inertial dynamics model to ensure the thermal comfort of customers. In [15], a residential load scheduling algorithm based on consumer's preferences is developed. In [16], the influence in comfort and uncertainty is expressed as a risk index, which is incorporated into the objective function to solve the optimization problem and guarantee the benefit to the consumer. The authors of Ref. [17] present an optimization method for scheduling home appliances that are expected to reduce the cost of operation and generation and, in doing so, shift the peak load without causing any discomfort. Thus, in the future, it will be essential to study how to avoid damaging the customer's lifestyle, and these factors must be taken into account, but this DSM cannot wholly take comfort into account.

This paper proposes an Advanced Direct Load Control (ADLC) model that temporarily shuts down the electric connection between the power grid and the smart house. The ADLC model does not shift the peak load as in the DLC; thus, allowing customers to operate their home appliances freely, which is "ideal" for customers and does not compromise their comfort. In addition, ADLC promotes the self-consumption of PV surplus power, which will not flow into the power grid; thus, improving the problems on the power grid side. In addition, during the shutdown period, self-consumption is expected to reduce the amount of electricity purchased by consumers, thereby decreasing the operating cost. At the same time, the carbon dioxide emission per $\mathrm{SH}$ is also reduced, which provides environmental benefits. In this paper, we calculate the operating costs and carbon dioxide emissions and discuss the impact of ADLC, aiming to create benefits for both consumers and power system operators.

The rest of this paper is organized as follows: In Section 2, we describe the proposed ADLC model. In Section 3, we present the SH model assumed in this paper. In Section 4, we present the objective function for operational cost minimization and the constraints considered in the optimization. In Section 5, we present the simulation conditions that we set up. In Section 6, the simulation results are presented and discussed. Section 7 concludes the paper.

\section{Advanced Direct Load Control (ADLC)}

Among the RES, the mass deployment of PV, in particular, mitigates global warming, but there are also disadvantages. As mentioned above, one of the issues on the power grid side is the duck curve. The duck curve is feared to cause a variety of problems from both economic and environmental perspectives, and RES output curtailment would also be necessary [18-20]. This has made it challenging to introduce new renewable energy sources. In order to address these issues, ADLC proposed in this paper is applied to smart houses.

The most important feature of the ADLC model is that the electric connection with the power grid is temporarily interrupted twice: during the daytime when the PV output is high and during the night time when the peak load is high. During the daytime shutdown period, the load demand of households is covered by the PV output, and if surplus power is generated, it is charged into storage batteries to promote private consumption. In this way, the power generated by PV does not flow into the power system during the daytime hours, and the power system as a whole can be given the same effect as PV output suppression. Therefore, the load demand of the entire power system during daytime hours would increase.

During the night-time shutdown period, the smart house is operated using the energy in the storage batteries charged with the surplus PV output during the daytime. This eliminates the need to purchase power from the power grid during the night-time shutdown period; thus, reducing the peak load at night for the power grid as a whole. In addition, since the smart house is operated only with the energy in the storage batteries during the night-time shutdown, the utilization rate of the storage batteries is also expected to 
improve. These merits mainly affect the power grid operation side and benefit the customer side, since the self-consumption of PV-generated electricity contributes to the reduction in the amount of purchased electricity and reduces the operation cost. Since the ADLC model reduces carbon dioxide emissions on a per-household basis, customers can participate in environmental conservation without adopting a "special" lifestyle.

In Section 1, we discussed the uncertainty of electricity consumption behavior on the customer side and the customer's comfort. When indirect control is applied to a smart house, the customer's consumption behavior affects the effect, and sufficient load shifting may not be realized. In the case of applying direct control to a smart house, the electric power company operates the home appliances installed in the smart house, and the customer must adjust their lifestyle to match the operation of the electric power company, which greatly impairs the comfort of the customer. In contrast, the ADLC model proposed in this paper shuts down the electric connection between the power system and the smart house; thus, modifying the load more reliably than indirect control. In addition, compared to direct control, the operation of home appliances can be tailored to the customer's preferences and, thus, comfort can be taken into account. At this time, worsening weather conditions or a disaster such as a typhoon would make it difficult to apply ADLC to the operation method. Therefore, it is assumed that ADLC can stop the shutdown upon the request of the consumer. Since typhoons and other natural phenomena are predictable, it is easy for consumers to obtain information about them through weather forecasts. In this way, ALDC is an operational method that can fully satisfy the demands of consumers.

\section{Smart House Model}

The smart house model assumed in this study is shown in Figure 1. The smart house is equipped with $\mathrm{PV}, \mathrm{HP}$, and stationary storage batteries. The connection point tidal current is the power tidal current supplied to the smart house from the power system in Figure 1. In this study, the HP and the stationary storage battery in the smart house were controllable loads, and the start-up and shutdown times of the HP and the charging and discharging power of the stationary storage battery were determined by an optimization problem that minimized the operation cost of the smart house. The capacity of the storage battery for stationary use was set to $5 \mathrm{~kW} / 13.5 \mathrm{kWh}$, and the HP water heater had a storage tank capacity of $370 \mathrm{~L}$, a rated heating capacity of $1 \mathrm{~kW} / 4 \mathrm{~kW}$, and a COP value of 4.0. The total amount of electricity consumed in the SH (for a total of $24 \mathrm{~h}$ ) was $15.4362 \mathrm{kWh}$, which was satisfied by the purchase of electricity, PV output, and battery discharge.

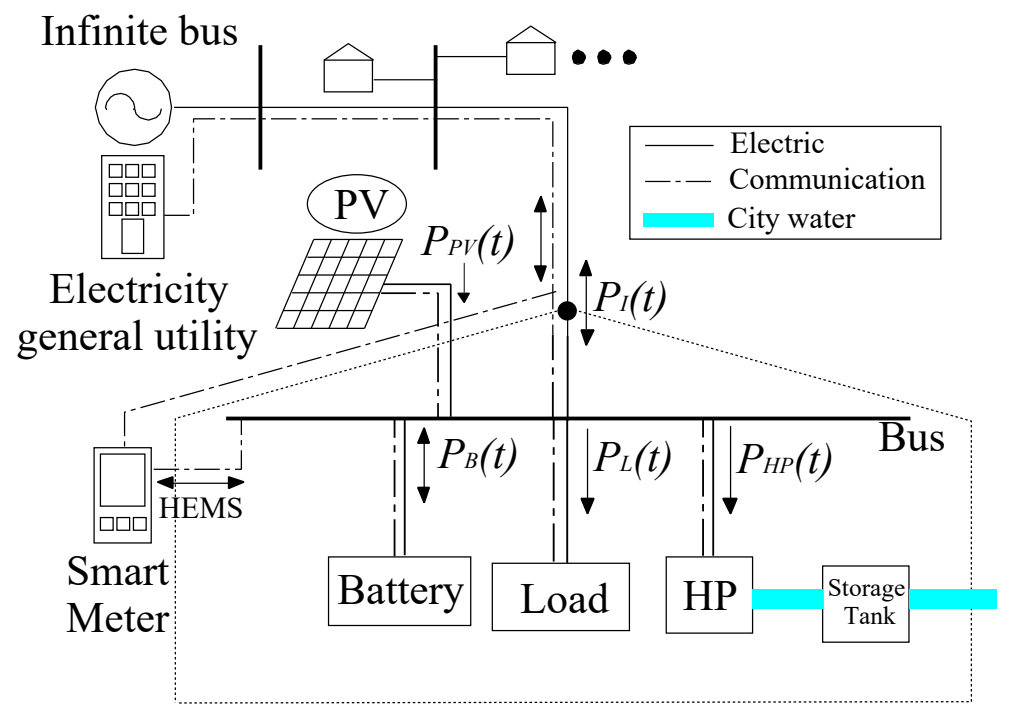

Figure 1. Smart house model. 
The parameters of the PV system covered in this paper were: conversion efficiency $\eta_{P V}=14.4 \%$, number of panels $n_{P V}=18$, area per panel $S_{P V}=1.3 \mathrm{~m}^{2}$, and rated output $P_{n}=3.5 \mathrm{~kW}$. The generated power $P_{P V}(\mathrm{~kW})$ of the PV obtained from the solar radiation was calculated from the following equation. Note that the simulations in this paper were conducted for Okinawa, Japan, and the solar radiation data for Okinawa were used for the simulations.

$$
P_{P V}=\eta_{P V} n_{P V} S_{P V} I_{P V}\left(1-0.005\left(T_{C R}-25\right)\right)
$$

where $I_{P V}\left(\mathrm{~kW} / \mathrm{m}^{2}\right)$ is the solar radiation and $T_{C R}\left({ }^{\circ} \mathrm{C}\right)$ is the outdoor air temperature.

\section{Formulation of Optimization Problem}

In Figure $1, P_{I}(t), P_{L}(t), P_{P V}(t), P_{B}(t)$, and $P_{H P}(t)$ indicate the power flow at the connection point of the smart house at each time $t$, the power consumption of all loads except the controllable load, the output of solar power generation, the charging/discharging power of storage batteries, and the power consumption of HP. The following equation was established from the relationship between the supply and demand balance in the smart house.

$$
P_{L}(t)-P_{P V}(t)-P_{B}(t)+P_{H P}(t)=P_{I}(t)
$$

\subsection{Objective Function}

The objective function was to minimize the total daily operating cost of the smart house. The objective function was shown below.

$$
\operatorname{Min}: \operatorname{Cost}_{\text {day }}=\sum_{t=1}^{24}\left(\operatorname{Cost}_{P}(t)-\operatorname{Cost}_{S}(t)\right)
$$

where $\operatorname{Cost}_{\text {day }}$ is the daily operating cost of the smart house, $\operatorname{Cost}_{P}(t)$ is the amount of electricity purchased, $\operatorname{Cost}_{S}(t)$ is the amount of electricity sold, and $t$ is the time.

\subsection{Constraints}

(a) Power flow variation constraint:

$$
\left|P_{I}(t)-P_{I}(t-1)\right|<P_{F B}
$$

where $P_{I(t-1)}$ is the power flow at the point of connection one time step ago and $P_{F B}$ is the maximum fluctuation of the power flow at the point of connection $(300 \mathrm{~W})$.

(b) Storage battery charging/discharging power constraint:

$$
\left|P_{B}(t)\right|<P_{B}^{\max }
$$

where $P_{B}(t)$ is the charging/discharging power of the stationary storage battery and $P_{B}^{\max }$ is the maximum charging/discharging power of the stationary storage battery. The positive direction of the current in the storage battery implies discharge.

(c) State of charge (SOC) constraint on storage batteries:

$$
C_{B}^{\min }<C_{B}(t)<C_{B}^{\max }
$$

where $C_{B}(t)$ is the SOC of the storage battery, $C_{B}^{\min }$ is the minimum storage battery capacity $(20 \%)$, and $C_{B}^{\max }$ is the maximum storage battery capacity $(90 \%)$.

(d) SOC constraint on storage batteries at the end of the day:

$$
0.5 C_{B}^{\max }<C_{B}(t=24)<0.7 C_{B}^{\max }
$$


In this paper, to shorten the simulation time, the weather classification introduced in Section 5.2 was performed and the operating cost for one month was calculated. Therefore, it was necessary to reconcile the charge rate of the storage battery because the operation for one year was not continuously simulated. Therefore, the problem was solved by setting the constraint conditions as described above.

(e) Shutdown constraint:

$$
P_{L}^{\text {shutdown }}-P_{P V}^{\text {shutdown }}-P_{B}^{\text {shutdown }}+P_{H P}^{\text {shutdown }}=0
$$

where $P_{L}^{\text {shutdown }}$ is the load power consumption other than controllable load during the shutdown period, $P_{P V}^{\text {shutdown }}$ is the PV power output during the shutdown period, and $P_{B}^{\text {shutdown }}$ is the storage battery charge/discharge power during the shutdown period. Since it was necessary to avoid power flow during the shutdown period, the power consumption in the smart house was satisfied by the PV output and the discharge of the storage battery. In addition, when surplus power was generated, the difference between the load of the smart house and the PV output was eliminated by charging the storage batteries.

(f) Constraints on the time of the shutdown period:

$$
\begin{gathered}
T_{F 1}-T_{S 1} \leq T_{\max } \\
T_{F 2}-T_{S 2} \leq T_{\max } \\
T_{S 2}-T_{F 1} \geq T_{\text {interval }}
\end{gathered}
$$

where $T_{S 1}$ indicates the first shutdown start time, $T_{F 1}$ indicates the first shutdown end time, $T_{S 2}$ indicates the second shutdown start time, $T_{F 2}$ indicates the second shutdown end time, $T_{\text {max }}$ indicates the maximum shutdown time, and $T_{\text {interval }}$ indicates the minimum shutdown interval.

\section{Operating Conditions}

In this paper, we determined the optimal operation method for controllable loads in a smart house by applying ADLC. Six case studies were considered, and the operational cost and carbon dioxide emissions of each were calculated. A summary of the case studies is given in Table 1. The simulations in this paper were performed using MATLAB R2020b on a PC with Intel Core i9-10980XE and 64GB of RAM. In the research of DSM, three methods were mainly employed to optimize the scheduling of controllable loads: mathematical programming, a heuristic approach, and meta-heuristic approach [21]. In this paper, Tabu Search (TS), a meta-heuristic solution method, was employed to solve the optimization problem. Genetic Algorithm (GA) is another well-known method [22]. TS was adopted in this paper because of its advantages such as having a relatively short computation time compared to other methods. The procedure for solving TS is represented in Figure 2. First, for any solution $x_{1}$, it searched for multiple neighboring solutions, selected a good solution $x_{2}$ from among them, and moved from $x_{1}$ to $x_{2}$. Then, it searched for the neighboring solutions again. In this way, the optimal solution was found by repeatedly searching for solutions. One of the biggest problems with meta-heuristic solutions is that they fall into local optimum solutions. In TS, we set up a tab list to avoid this problem. The "tab-list" was a list that stored the solutions we had moved so far, and we avoided the risk by searching for solutions while referring to the tab list. In this paper, a limit was placed on the storage memory of the tabular list, which was updated in order of the oldest solution. The parameters set for applying TS are shown in Table 2. 
Table 1. Case studies.

\begin{tabular}{cccc}
\hline Case & ADLC & Electricity Sales Price (JPY/kWh) & SH Model \\
\hline Case 1 & w/o & 19.0 & \\
Case 2 & w/ & 19.0 & Traditional \\
Case 3 & w/o & 7.7 & \\
Case 4 & w/ & 7.7 & Self-consumption \\
\hline Case 5 & w/o & - & \\
Case 6 & w/ & - & \\
\hline
\end{tabular}

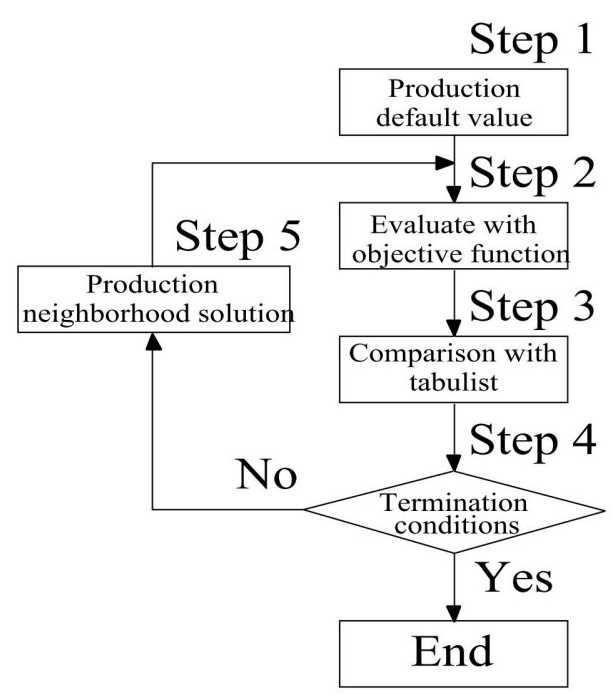

Figure 2. Flow chart of Tabu Search.

Table 2. Parameters set in TS.

\begin{tabular}{cc}
\hline Parameters & Set Value \\
\hline Number of searches & 2000 \\
Storage capacity of tab list & 500 \\
\hline
\end{tabular}

\subsection{Hot Water Demand}

Hot water use is one of the important factors in consumer consumption behavior. In this paper, we assumed that the SH model used hot water twice a day, once in the morning and once in the evening, and the water used in the SH was managed in a tank attached to the HP water heater and supplied to the SH. When the water temperature in the tank was lower than the target temperature, the HP was activated to heat the water. The parameters for hot water use are summarized in Table 3.

Table 3. Parameters for hot water usage.

\begin{tabular}{ccc}
\hline Parameters & The Morning & The Evening \\
\hline Use time & $7: 00 \sim 8: 00$ & $20: 00 \sim 23: 00$ \\
Supply completion time & $7: 00$ & $20: 00$ \\
\hline Target temperature & $50{ }^{\circ} \mathrm{C}$ & $60^{\circ} \mathrm{C}$ \\
Amount used & $30 \mathrm{~L}$ & $150 \mathrm{~L}$ \\
\hline
\end{tabular}

\subsection{Weather Classification}

In this paper, to reduce the simulation time, we classified the weather conditions and performed simulations for each weather condition to calculate the operational cost. First, we simulated one day in each weather condition (sunny, cloudy, and rainy). Next, the 
percentage of sunny, cloudy, and rainy days in the target month was calculated based on the maximum solar radiation for each month. We defined a sunny day as one that was $60 \%$ or more of the maximum solar radiation in the target month, a cloudy day as one that was $30 \%$ or closer to $60 \%$, and a rainy day as one that was less than $30 \%$. This definition determined the number of days in each weather condition and the simulation for each weather condition was used to calculate the monthly operating cost.

The power consumption other than the controllable load assumed in this paper and the PV power output in each weather condition are shown in Figure 3. The simulations were conducted for each month from January to December, and the simulation results for October were shown as a representative.

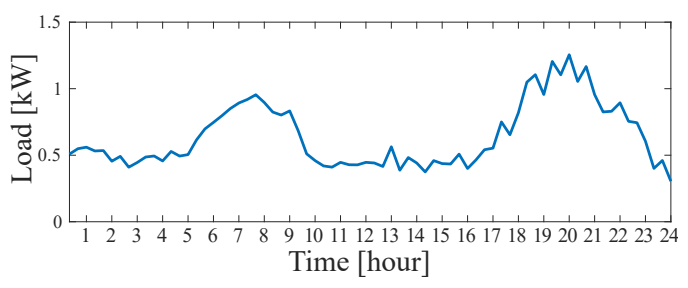

(a)

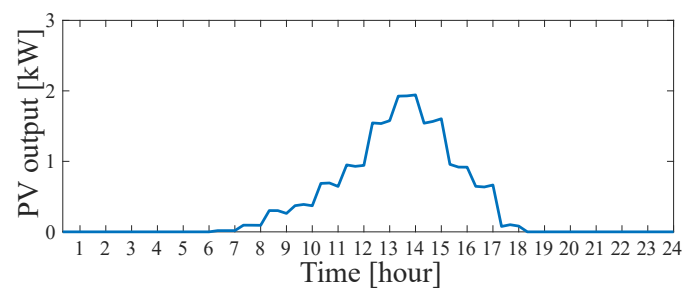

(c)

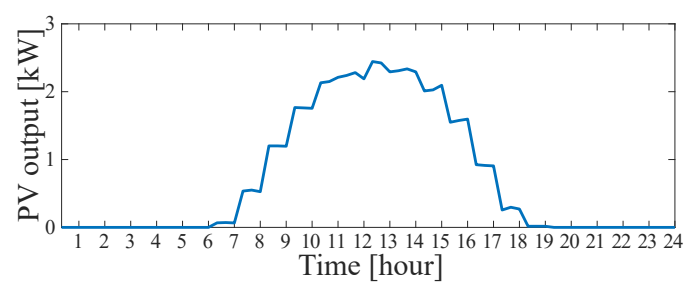

(b)

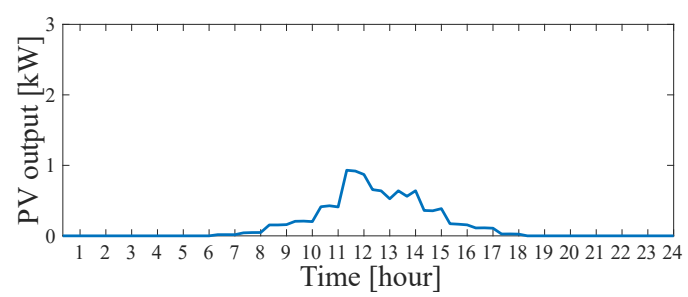

(d)

Figure 3. Load in SH and PV output (Oct.). (a) Power consumption; (b) PV output power on sunny day; (c) PV output power on cloudy day; (d) PV output power on rainy day.

\subsection{Application of ADLC}

ADLC was applied to the $\mathrm{SH}$ according to the following rules. An example of ADLC application is shown in Figure 4.

- The shutdown would be performed twice a year, once during the day when PV output was high and once at night when peak load occurred.

- The shutdown time per time shall be $2 \mathrm{~h}$ (6 time steps).

- The interval between the first and second shutdown periods must be at least $2 \mathrm{~h}$.

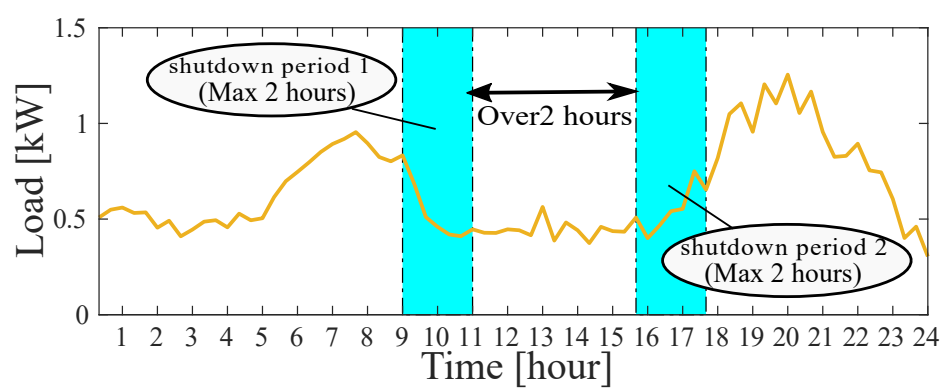

Figure 4. Example of ADLC application.

\section{Simulation Results}

\subsection{Operation of $\mathrm{SH}$}

In this paper, we set the ToU price where the electricity price was set for each time period. The FIT price for electricity sales was the unit price set by the Japanese government. The unit price table is shown in Table 4 [23]. The simulation results for sunny, cloudy, and 
rainy days are shown in Figures 5-7. Figures 5a-7a show the operating/stopping status of the HP. On sunny days, the HP was operated using inexpensive late-night electricity and PV output, so it was operated during the late-night hours and the hours of high solar radiation from morning to daytime. In rainy and cloudy weather, when solar radiation was low, a part of the increased power consumption due to the HP operating was covered by the PV output, and the rest was operated by discharging the storage batteries and purchasing power.

Table 4. Electricity rate.

\begin{tabular}{|c|c|c|c|c|}
\hline Type of Service & Type & vice & Unit & Unit Charge (JPY) \\
\hline Basic Charge & & & - & 1620.00 \\
\hline \multirow{4}{*}{ Energy Charge } & \multirow{2}{*}{ Daytime } & Summer & \multirow{6}{*}{$1 \mathrm{kWh}$} & 38.65 \\
\hline & & Others & & 35.23 \\
\hline & \multicolumn{2}{|c|}{ Living Time } & & 26.71 \\
\hline & $\mathrm{Ni}$ & & & 10.97 \\
\hline \multirow{2}{*}{ Sales price } & \multicolumn{2}{|c|}{ FIT price } & & 19.00 \\
\hline & \multicolumn{2}{|c|}{ Non-FIT price } & & 7.70 \\
\hline
\end{tabular}

Daytime : 10:00 17:00; Living time : 7:00 10:00/17:00 23:00; Night time : 23:00 7:00.

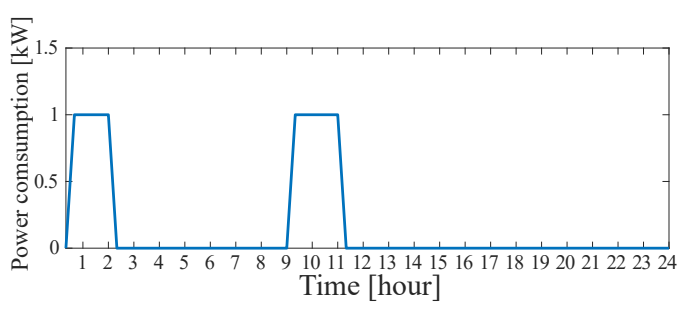

(a)

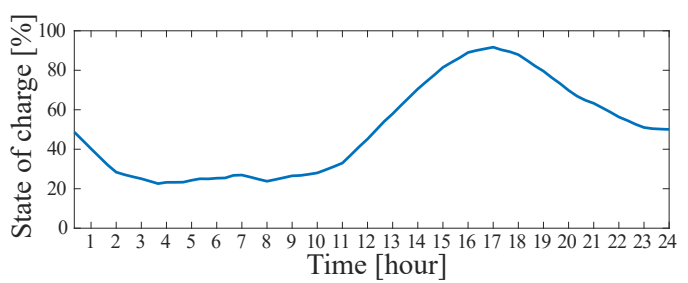

(c)

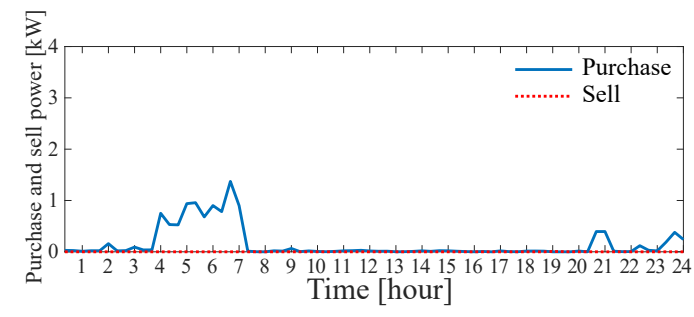

(b)

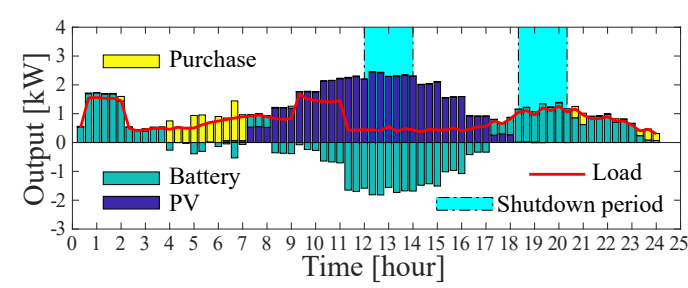

(d)

Figure 5. Simulation results on sunny day (Oct.). (a) Power consumption of HP; (b) purchased and sold power; (c) SOC for storage battery; (d) operation of SH.

The purchased and sold power in each weather condition is shown in Figures $5 b-7 b$, where it can be confirmed that no power was sold because all the power generated by PV was consumed by itself. In this paper, the first shutdown time was from 12:00 to 14:00 when the PV output was large, and the second shutdown time was from 18:20 to 20:20 when the peak load occurred. It can be confirmed that the amount of electricity purchased was zero during the night-time shutdown period. After that, the energy in the storage batteries contributed to reducing purchasing power from evening to night time. In addition, during sunny and cloudy days, the amount of purchased electricity was reduced through the self-consumption of PV-generated electricity.

The behavior of the storage battery as a controllable load is shown in Figures 5c-7c. During sunny and cloudy weather, the energy in the storage batteries increased during the daytime hours when electricity was purchased or the amount of solar radiation was high, and the amount of energy decreased from evening to night time. Furthermore, during the second shutdown period, the energy in the storage batteries was used to cover the load 
power consumption of the smart house, and it can be confirmed that the stored energy decreased. It can be confirmed that the storage batteries were being recharged using inexpensive night-time electricity and discharged starting in the evening hours, as the PV system generated little power during rainy weather.

The output and purchased power of each facility during a day's operation of the smart house is shown in Figures $5 \mathrm{~d}-7 \mathrm{~d}$. As mentioned above, the shutdown periods were implemented from 12:00 to 14:00 and from 18:20 to 20:20. In the daytime shutdown period, it could be confirmed that the load power consumption generated by the $\mathrm{SH}$ was satisfied by the PV output. During the night-time shutdown, the smart house was operated by discharging the energy charged by the surplus electricity generated by the PV during the daytime or using inexpensive night-time electricity [24-26].

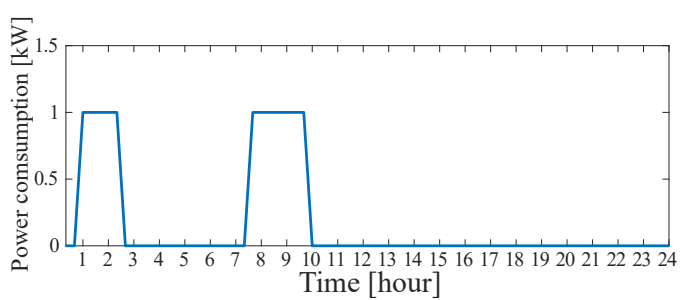

(a)

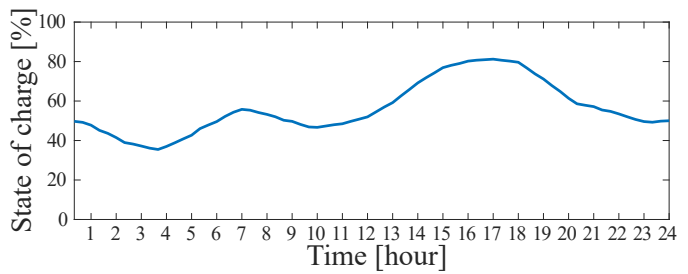

(c)

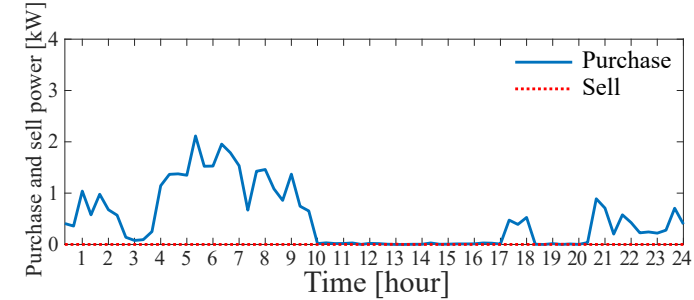

(b)

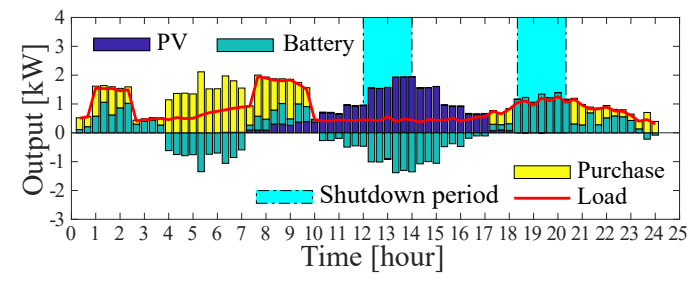

(d)

Figure 6. Simulation results on cloudy day (Oct.). (a) Power consumption of HP; (b) purchased and sold power; (c) SOC for storage battery; (d) operation of SH.

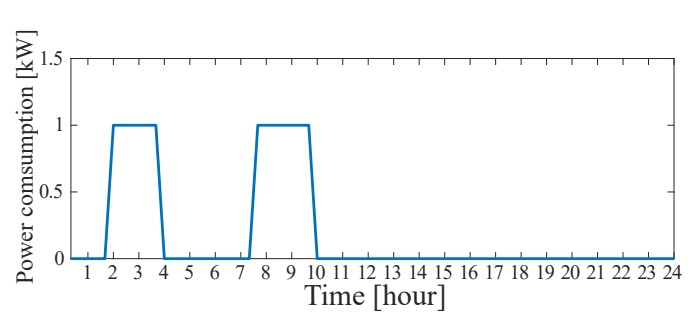

(a)

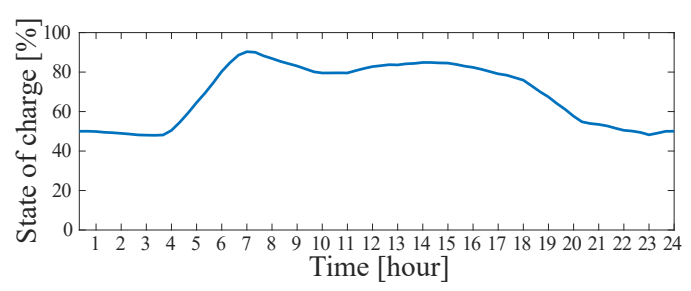

(c)

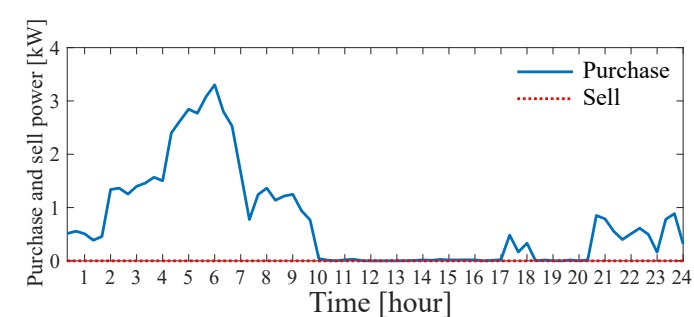

(b)

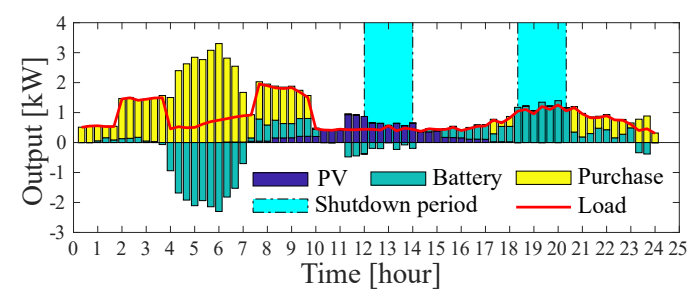

(d)

Figure 7. Simulation results on rainy day (Oct.). (a) Power consumption of HP; (b) purchased and sold power; (c) SOC for storage battery; (d) operation of SH.

\subsection{Operational Results of Other Case Studies}

Section 6.1 referred to the operational results of the SH in Case 6. In this section, we discuss the results of the other case studies. Figure 8 shows the results of the $\mathrm{SH}$ operation 
in Case 1 to Case 5. In Case 1 and Case 2, where the FIT price was adopted as the power sale price, the basic operation policy was to sell most of the PV surplus power. As can be seen from Equation (3), the income of the consumer from the sale of electricity was a variable that influenced the objective function, and in Cases 1 and 2, the large income from the sale of electricity at the FIT price led to the operation method shown in the figure. In Case 1, the storage batteries were recharged during the late night hours when electricity rates were low (1:00 to 7:00) and discharged during the night-time hours when PV output was not available (18:00 to 24:00). However, since ADLC was applied to Case 2, it could be confirmed that the storage batteries were charged during the shutdown period. As mentioned earlier, the power tidal current was reduced to zero during the shutdown period, so surplus power was not sold, but was instead consumed in-house.

Figure $8 c, d$ shows the results of the operation of Case 3 and Case 4 . In this case, it could be confirmed that the percentage of surplus power used to charge the storage batteries increased because the revenue from power sales was smaller than in Case 1 and Case 2. As a result, a time when the power tidal current became zero occurred, and it could be confirmed that PV surplus power was being charged and discharged at night.

Figure 8e shows the operational results in Case 5, which was a self-consumption SH that used all the generated electricity to operate the loads in the $\mathrm{SH}$, so $P_{I}(t) \geq 0$ was always obtained. Therefore, the amount of electricity purchased would be the minimum necessary, and the carbon dioxide emissions per SH house would be reduced proportionally. This was discussed in detail in Section 6.3.

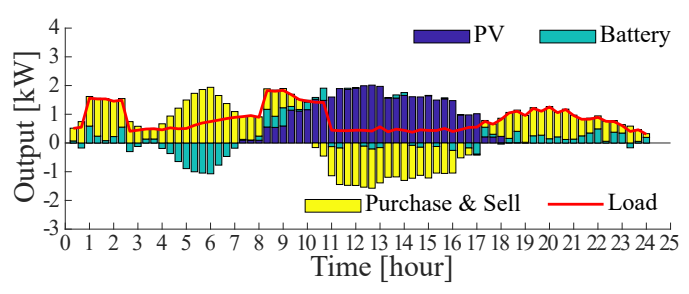

(a)

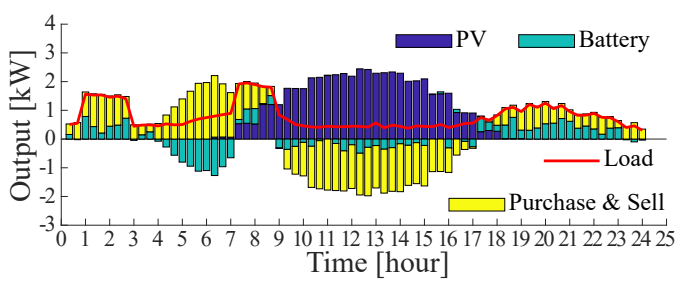

(c)

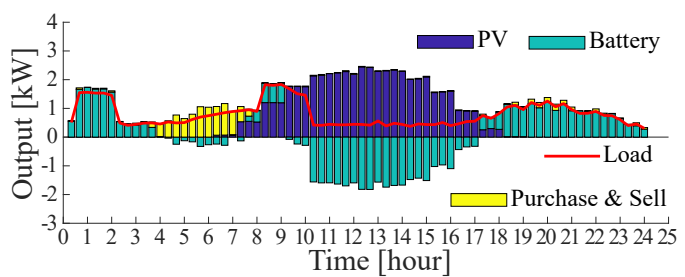

(e)

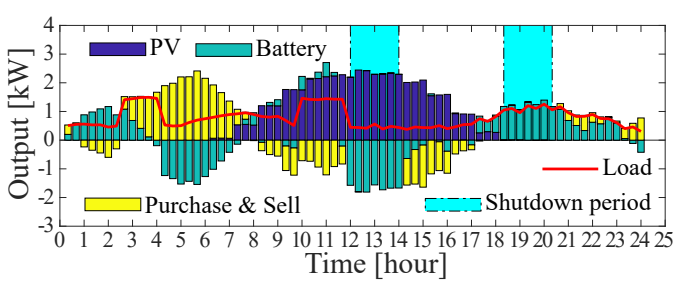

(b)

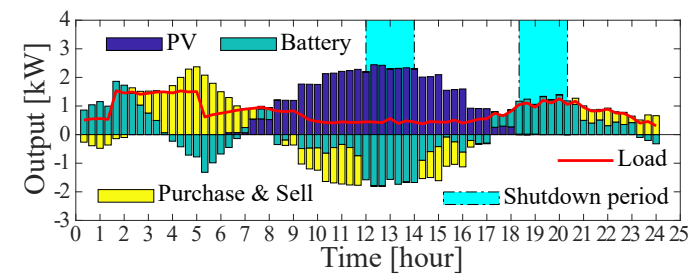

(d)

Figure 8.
(e) Case 5 .

\subsection{Comparison and Discussion of Operating Costs and $\mathrm{CO}_{2}$ Emissions}

In this paper, an $\mathrm{SH}$ was simulated in six case studies, and the operating cost for one year was calculated from the simulation results of each weather condition in each month. The operating cost of the smart house in each case study is shown in Table 5. Comparing Case 1 and 2, it can be confirmed that there was a difference in the purchase price depending on whether ADLC was applied or not. This was because the application of ADLC reduced 
the amount of purchased electricity by consuming PV-generated electricity in the SH during the shutdown period. In addition, comparing Case 1 and 5, it can be confirmed that the amount of purchased electricity was reduced by supplying surplus electricity generated by $\mathrm{PV}$ to the load in the SH instead of selling it. The above simulation results showed that the application of ADLC to a self-consumption SH reduced the purchase price the most among all case studies.

In recent years, there has been a need to reduce carbon dioxide emissions in the household sector due to the growing interest in environmental issues such as global warming. This paper calculated the carbon dioxide emissions per SH household based on the purchased electricity for one year. The carbon dioxide emissions in each case are shown in Table 5. From the simulation results, it can be confirmed that the application of ADLC reduced carbon dioxide emissions as the purchased electricity was controlled. In addition, the self-consumption-type $\mathrm{SH}$ without power sales reduced the carbon dioxide emissions compared to the conventional SH (with power sales). Based on these simulation results, Case 6, which applied ADLC to a self-consumption $\mathrm{SH}$, had the most significant potential to reduce carbon dioxide emissions. Therefore, it can be confirmed that Case 6 was superior to the other cases regarding environmental friendliness.

Table 5. Operation costs and $\mathrm{CO}_{2}$ emissions in $\mathrm{SH}$.

\begin{tabular}{ccccc}
\hline Case & $\begin{array}{c}\text { Purchase } \\
\text { (JPY) }\end{array}$ & $\begin{array}{c}\text { Sell } \\
(\mathbf{J P Y})\end{array}$ & $\begin{array}{c}\text { Operation Cost } \\
(\mathbf{J P Y})\end{array}$ & $\begin{array}{c}\mathbf{C O}_{\mathbf{2}} \text { Emission } \\
\left(\mathbf{t}-\mathbf{C O}_{\mathbf{2}} \mathbf{)}\right.\end{array}$ \\
\hline Case 1 & 100,680 & 85,695 & 14,985 & 4.62 \\
Case 2 & 78,666 & 77,141 & 1525 & 3.98 \\
Case 3 & 81,289 & 14,757 & 66,532 & 3.69 \\
Case 4 & 67,444 & 12,953 & 54,491 & 2.84 \\
Case 5 & 70,131 & 0 & 70,131 & 2.56 \\
Case 6 & 67,398 & 0 & 67,398 & 2.53 \\
\hline
\end{tabular}

\section{Conclusions}

This paper proposed an optimal operation method of a controllable load in an $\mathrm{SH}$ with advanced direct load control (ADLC) to minimize the daily operating cost. From the simulation results, the operating cost for one year was calculated and compared with the operating cost in an $\mathrm{SH}$ for each case study. ToU prices, set according to the time of day and season, were used to calculate the operational costs. In addition, TS, a meta-heuristic solution method, was adopted as the solution method of the optimization problem to minimize the operation cost, and the operation method of the controllable load, storage battery and HP, were determined. The simulation results showed that it was possible to reduce purchasing power by supplying the surplus power from PV generation to the loads in the $\mathrm{SH}$ without selling power and consuming all the power in the $\mathrm{SH}$. In addition, the application of ADLC to the self-consumption SH was found to reduce the operating cost. In addition, carbon dioxide emissions per $\mathrm{SH}$ were reduced by reducing the amount of purchased electricity. This showed that self-consumption SHs with ADLCs are environmentally superior; self-consumption in SHs allowed for a more efficient generator operation since the renewable energy-generated power did not flow into the power system. This was expected to reduce the operating costs of the generators and benefit the power supply side as well. Furthermore, electricity consumers would see a decrease in their electricity bills, which would promote the shift to $\mathrm{SH}$ and contribute to the expansion of the introduction of renewable energy.

In the future, the integration of electric vehicles (EVs), detailed HP models, and the uncertainty of PV power generation will be introduced into the simulations. EVs are expected to bring out more potential than their capacity as vehicles by operating them as storage batteries in an $\mathrm{SH}$. This will promote the introduction of EVs and further reduce the progress of global warming. Determining the optimal configuration and capacity of the equipment to be installed in an $\mathrm{SH}$ is an important issue to address in the future. In 
$\mathrm{HP}$, the water is usually divided into two layers in the hot water storage tank at different temperatures. By constructing a detailed $\mathrm{HP}$ model, the required power demand in $\mathrm{SH}$ can be accurately assumed. In addition, the uncertainty of the PV system must be taken into account because the power generated depends on the weather. This has become an essential issue in the expansion of renewable energy deployment.

Author Contributions: Conceptualization, K.T. and T.S.; methodology, K.T.; software, K.T.; validation, K.T. and T.S.; formal analysis, T.A., A.M.H. and N.K.; investigation, K.T.; resources, A.M. and M.E.L.; data curation, K.T.; writing—original draft preparation, K.T.; writing—review and editing, T.A., A.M. and N.K.; visualization, A.M.H. and M.E.L.; supervision, K.T. and T.S.; project administration, T.S. All authors have read and agreed to the published version of the manuscript.

Funding: This research received no external funding.

Conflicts of Interest: The authors declare no conflict of interest.

\section{Abbreviations}

The following abbreviations are used in this manuscript:

\begin{tabular}{|c|c|}
\hline $\mathrm{SH}$ & Smart House \\
\hline $\mathrm{HP}$ & Heat Pump \\
\hline ToU & Time-of-Use \\
\hline DR & Demand Response \\
\hline DSM & Demand-side Management \\
\hline RTP & Real-time Pricing \\
\hline $\mathrm{SOC}$ & State of charge \\
\hline ADLC & Advanced Direct Load Control \\
\hline \multicolumn{2}{|c|}{ Variables in the manuscript: } \\
\hline$t$ & Time \\
\hline shutdown & Variables in shutdown period \\
\hline$P_{P V}$ & PV output \\
\hline$\eta_{P V}$ & Conversion efficiency \\
\hline$n_{P V}$ & Number of PV panels \\
\hline$S_{P V}$ & Area per PV panel \\
\hline$I_{P V}$ & Solar radiation \\
\hline$T_{C R}$ & Outdoor air temperature \\
\hline$P_{I}$ & Power flow at the connection point \\
\hline$P_{L}$ & Power consumption except the controllable load \\
\hline$P_{P V}$ & PV output \\
\hline$P_{B}$ & Charging/discharging power \\
\hline$P_{H P}$ & Power consumption of HP \\
\hline $\operatorname{Cost}_{\text {day }}$ & Daily operating cost of $\mathrm{SH}$ \\
\hline $\operatorname{Cost}_{P}$ & Electricity purchased \\
\hline $\operatorname{Cost}_{S}$ & Electricity sold \\
\hline$P_{F B}$ & Maximum fluctuation of the power flow \\
\hline$P_{B}^{\max }$ & Maximum charging/discharging power \\
\hline$C_{B}$ & SOC of battery \\
\hline$C_{B}^{\min }$ & Minimum storage capacity \\
\hline$C_{B}^{\max }$ & Maximum storage capacity \\
\hline$T_{S 1}^{D}$ & First shutdown start time \\
\hline$T_{F 1}$ & First shutdown finish time \\
\hline$T_{S 2}$ & Second shutdown start time \\
\hline$T_{F 2}$ & Second shutdown finish time \\
\hline$T_{\max }$ & Maximum shutdown time \\
\hline$T_{\text {interval }}$ & Minimum shutdown interval \\
\hline
\end{tabular}




\section{References}

1. Liang, B.; Liu, W.; Sun, L.; He, Z.; Hou, B. Economic MPC-Based Smart Home Scheduling With Comprehensive Load Types, Real-Time Tariffs, and Intermittent DERs. IEEE Access 2020, 8, 194373-194383. [CrossRef]

2. Tanaka, K.; Uchida, K.; Ogimi, K.; Goya, T.; Yona, A.; Senjyu, T.; Funabashi, T.; Kim, C. Optimal Operation by Controllabel Loads based on Smart Grid Topology Considering Insolation Forecasted Error. IEEE Trans. Smart Grid 2011, 2, 438-444. [CrossRef]

3. Somma, M.D.; Graditi, G.; Heydarian-Forushnai, E.; Shafie-khah, M.; Siano, P. Stochastic optimal scheduling of distributed energy resources with renewables considering economic and enviromental aspects. Renew. Energy 2018, 116, $272-287$.

4. Shimoji, T.; Tahara, H.; Matayoshi, H.; Yona, A.; Senjyu, T. Comparison and Validation of Operational Cost in Smart Houses with Introduction of a Heat Pump or a Gas Engine. Int. J. Emerg. Electr. Power Syst. 2015, 16, 59-74. [CrossRef]

5. Oprea, S.V.; Bâra, A.; Ifrim, G. Flattening the electricity consumption peak and reducing the electricity payment for residential consumers in the context of smart grid by means of shifting optimization algorithm. Comput. Ind. Eng. 2018, 122, 125-139. [CrossRef]

6. Pallonetto, F.; Oxizidis, S.; Milano, F.; Finn, D. The effect of time-of-use tariffs on the demand response flexibility of an all-electric smart-grid-ready dwelling. Energy Build. 2016, 128, 56-67. [CrossRef]

7. Hou, Q.; Zhang, N.; Du, E.; Miao, M.; Peng, F.; Kang, C. Probabilistic duck curve in high PV penetration power system: Consept, modeling, and empirical analysis in China. Appl. Energy 2019, 242, 205-215. [CrossRef]

8. Howlader, H.O.R.; Sediqi, M.M.; Ibrahimi, A.M.; Senjyu, A.T. Optimal Thermal Unit Commitment for Solving Duck Curve Problem by Introducing CSP, PSH and Demand Response. IEEE Access 2018, 6, 4834-4844. [CrossRef]

9. Lu, Q.; Zhang, Z.; Lu, S. Home energy management in smart households: Optimal appliance scheduling model with photovoltaic energy storage system. Energy Rep. 2020, 6, 2450-2462. [CrossRef]

10. Hosseini, S.M.; Carli, R.; Dotoli, M. Model predictive control for real-time residential energy scheduling under uncertainties. In Proceedings of the 2018 IEEE International Conference on Systems, Man, and Cybernetics (SMC), Miyazaki, Japan, 7-10 October 2018; pp. 1386-1391.

11. Javadi, M.S.; Gough, M.; Lotfi, M.; Nezhad, A.E.; Santos, S.F.; Catalao, J.P.S. Optimal self-scheduling of home energy management system in the presence of photovoltaic power generation and batteries. Energy 2020, 210, 118568. [CrossRef]

12. Tumuluru, V.K.; Tsang, D.H.K. A two-stage approach for network constrained unit commitment problem with demand response. IEEE Trans. Smart Grid 2016, 9, 1175-1183. [CrossRef]

13. Rastegar, M.; Fotuhi-Firuzabad, M. Outage management in residential demand response programs. IEEE Trans. Smart Grid 2014 6, 1453-1462. [CrossRef]

14. Luo, F.; Zhao, J.; Wang, H.; Tong, X.; Chen, Y.; Dong, Z.Y. Direct load control by distributed imperialist competitive algorithm. J. Mod. Power Syst. Clean Energy 2014, 2, 385-395. [CrossRef]

15. Jiang, X.; Wu, L. A Residential Load Scheduling Based on Cost Efficiency and Consumer's Preference for Demand Response in Smart Grid. Electr. Power Syst. Res. 2020, 186, 106410. [CrossRef]

16. Kong, X.; Sun, B.; Kong, D.; Li, B. Home energy management optimization method considering potential risk cost. Sustain. Cities Soc. 2020, 62, 102378. [CrossRef]

17. Zhu, H.; Gao, Y.; Hou, Y.; Wang, Z.; Feng, X. Real-time pricing considering different type of smart home appliances based on Markov decision process. Int. J. Electr. Power Energy Syst. 2019, 107, 486-495. [CrossRef]

18. Wang, Q.; Chang, P.; Bai, R.; Liu, W.; Dai, J.; Tang, Y. Mitigation Strategy for Duck Curve in High Photovoltaic Penetration Power System Using Concentrating Solar Power Station. Energies 2019, 12, 3521. [CrossRef]

19. Hernandez, J.C.; Medina, A.; Jurado, F. Optimal Allocation and sizing for profitability and voltage enhancement of PV systems on feeders. Renew. Energy 2007, 32, 1768-1789. [CrossRef]

20. Ning, J.; Tang, Y.; Chen, Q.; Wang, J.; Zhou, J.; Gao, B. A Bi-Level Coordinated Optimization Strategy for Smart Appliances Considering Online Demand Response Potentail. Energies 2017, 10, 525. [CrossRef]

21. Golmohamadi, H.; Keypour, R.; Bak-Jensen, B.; Pillai, J.R. Optimization of household energy consumption towards day-ahead retail electricity price in home energy management systems. Sustain. Cities Soc. 2019, 47, 101468. [CrossRef]

22. Panichella, A.; Oliveto, R.; Penta, M.D.; DeLucia, A. Improving Multi-Objective Test Case Selection by Injecting Diversity in Genetic Algorithms. IEEE Trans. Softw. Eng. 2015, 41, 358-383. [CrossRef]

23. Ee-Home Holiday, The Okinawa Electric Power Company, Incorporated. Available online: https://www.okiden.co.jp/en/ customer/erm/holiday.html (accessed on 3 September 2021).

24. An, J.; Mikhaylov, A.; Jung, S.-U. A Linear Programming Approach for Robust Network Revenue Management in the Airline Industry. J. Air Transp. Manag. 2021, 91, 101979. [CrossRef]

25. Mikhaylov, A. Development of Friedrich von Hayek's theory of private money and economic implications for digital currencies. Terra Econ. 2021, 19, 53-62. [CrossRef]

26. An, J.; Mikhaylov, A.; Richter, U.H. Trade War Effects: Evidence from Sectors of Energy and Resources in Africa. Heliyon 2020, 6, e05693. [CrossRef] 